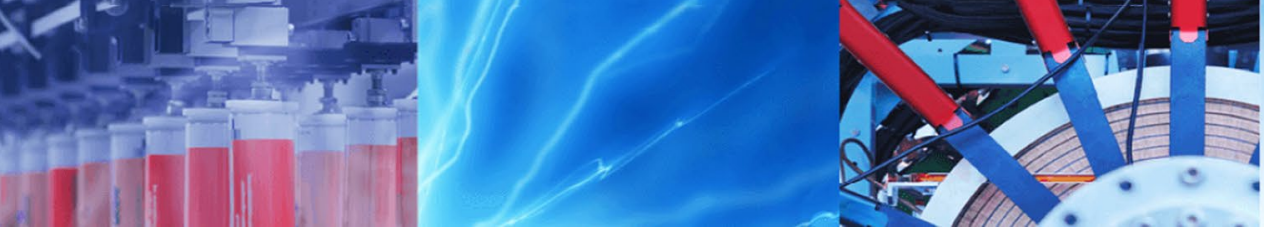

Research Article

\title{
Valorization of post-consumer polythene water sachet and Parinari polyandra shell residue for composites production
}

\author{
T. E. Odetoye ${ }^{1}$ (D. A. G. Adeniyi ${ }^{1} \cdot$ O. Akande ${ }^{1}$
}

Received: 6 May 2020 / Accepted: 7 October 2020 / Published online: 15 October 2020

(c) Springer Nature Switzerland AG 2020

\begin{abstract}
Mitigation of the environmental burden associated with indiscriminate disposal of post-consumer low density polyethylene (LDPE) packaging material is receiving attention in recent times. There is a need to search for alternative reuse of the accumulating plastic wastes constituting pollutants in our environment. This work involves the preparation and evaluation of the bio-composite samples from post-consumer low density polyethylene water sachets and parinari fruits shell. Biocomposite samples of filler percentages 10, 20 and 30\% were produced. The mechanical properties of the samples were determined as function of filler content and particle size according to ASTM standards and confirmed with SEM. The samples had desirable hardness strength of $4568.9 \mathrm{~N} / \mathrm{mm}^{2}$ and desirable biodegradability for $30 \%$ filler weight of particle size $4 \mathrm{~mm}$. The biocomposite samples exhibited desirable impact $\left(51.75 \mathrm{~kJ} / \mathrm{m}^{2}\right)$, tensile (10.02) and flexural strength $\left(18.23 \mathrm{~N} / \mathrm{mm}^{2}\right)$ with the $10 \%$ weight samples. The findings in this study suggest that post-consumer LDPE wastes can be valorized by conversion to biocomposites using biomass wastes such as parinari shell as cheap value-addition material, providing a cheap potential waste management method for solving the global plastic waste crisis.
\end{abstract}

Keywords Waste polyethylene sachet $\cdot$ Biocomposite $\cdot$ Parinari residue $\cdot$ Waste management

\section{Introduction}

The environmental burden constituted by post-consumer plastic wastes which include low density polyethylene (LDPE) bags, films and sachets cannot be over-emphasized [1]. The havoc wreaked to the environment through incineration of such plastic wastes and the problem of decreasing landfill capacities have necessitated global research efforts to be directed towards the conversion of such polymer wastes to value added products [2]. More than 50 million tonnes of post-consumer plastics wastes are generated yearly in Europe, USA and Japan [3] leading to ban of plastic bags in certain countries [1]. In most developing countries, LDPE sachet is commonly used for packaging water, resulting in large volumes of post-consumer plastic wastes that currently constitute a serious environmental challenge [4].
LDPE is widely used because of ease of processing which is enabled by LDPE macromolecules that are not tightly packed because the highly branched chain partly impedes alignment of the methylene chain. Other desirable properties include chemical resistance, flexibility, tensile strength, tear strength, even at relatively low temperatures [5-10]. Although, LDPE packaging materials are durable and are able to preserve contents due to the unreactive nature they are non-biodegradable. This same durability property is unfortunately the reason for the lingering post-consumer plastic bags, films, sachet in the environment.

Recycling as a measure of addressing plastic waste pollution challenge is associated with the weakness of undesirable mechanical, thermal and other relevant properties of the recycled product [11]. Therefore, natural fibers have been harnessed as reinforcing filler in the polymer matrix

T. E. Odetoye, todetoye@yahoo.com | 'Department of Chemical Engineering, University of Ilorin, P.M.B. 1515, Ilorin, Kwara, Nigeria. 
and to enhance biodegradability of the recycled plastics in biocomposites production [12]

Biocomposites are materials in which at least one of the components can be considered as bio-based. They are made from the combination of natural fiber (biomass) and a matrix with the resulting material having more desirable properties than either of the parent materials. Such advantages include imparting properties such as strength and biodegradability.

Several biomasses have been investigated as fillers in LDPE polymer matrix, these include breadfruit seed coat [13], olive stone [11], snail shell [14] wood fiber [15], palm kernel shell fiber [16], groundnut shell [17]. Recent works also reported other applications of LDPE waste as construction materials in plastic bonded sand block [9], lightweight concrete [18] and hydrophobic surface coating [19].

Natural fibers can be obtained from a variety of plants with lignocellulosic material. The fruit shell of Parinari polyandra Benth is a residue with relatively high lignocellulose content that has been scarcely harnessed. Parinari polyandra Benth (aka Maranthes polyandra Benth) is a Rosacea family savannah plant that is available in West Africa extending from Mali to Sudan [20]. Ripe fruits of the plant are usually smooth and about $2.5 \mathrm{~cm}$ long having a deep red or blackish purple color depending on the variety (Fig. 1). The endosperm has a yellow white appearance with a thick seed coat containing the oily mass. The oil obtained from the seed kernel (up to $60 \%$ oil content) has been found to be suitable for alkyd resin synthesis with desirable drying characteristics [21, 22]. However, the fruit shells constitute a waste needed to be valorized to enhance the oil production process. The thermochemical properties obtained for parinari fruit shell including ultimate, inorganic, and proximate analyses have been earlier reported [20]. This work reports the utilization of parinari fruit shell for biocomposite preparation for the first time.

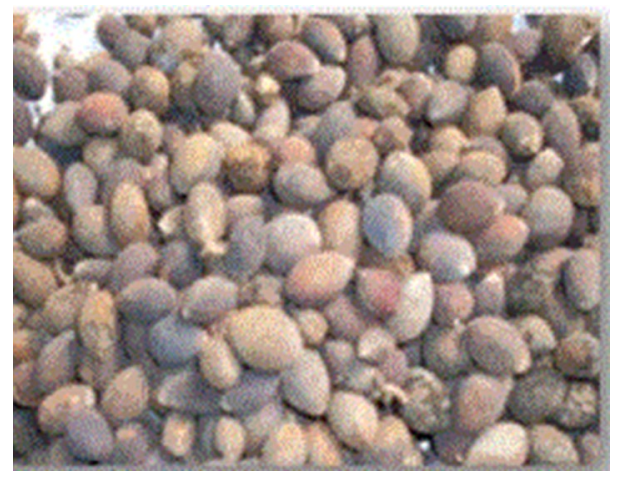

Fig. 1 Parinari polyandra B. fruits

\section{Materials and methods}

\subsection{Materials}

The post-consumer polyethylene water sachets were collected locally from restaurants at the University of Ilorin, Ilorin, Kwara State, Nigeria while parinari fruits shells were obtained from Chemical Engineering Research Laboratory, University of Ilorin as residues of parinari oil production process. The parinari fruits were originally harvested from trees at the same campus.

\subsection{Methods}

\subsubsection{Filler and matrix materials preparations}

The biomass filler material, parinari fruit shells particle (PFSP) was prepared from parinari fruit shells. The shells were cleaned to remove sands and other impurities and sundried for 5 days. Size reduction was achieved for about $1 \mathrm{~kg}$ of dried parinari fruit shells with the use of hammer milled pulverizing machine. The particles obtained (Fig. 2) were categorized using BS sieves of mesh numbers 5, 20 and 40 into $X_{1}, X_{2}$ and $X_{3}$ which correspond to $4,0.84$ and $0.42 \mathrm{~mm}$ parinari fruit shells particle (PFSP) sizes respectively of uniform particle sizes. The waste polythene sachets were sorted, rinsed with distilled water at room temperature and sundried for 5 days. The films were then shredded to about $1 \mathrm{~cm}^{2}$ size.

\subsubsection{Preparation of PFSP-polyethylene composites}

$\mathrm{Xg}$ of the polyethylene shreds were charged into a hot plate-heated saucepan and allowed to melt for about $8 \mathrm{~min}$. The melting occurred within the temperature of $100-110^{\circ} \mathrm{C}$. Then, $\mathrm{Y} \mathrm{g}$ of PFSP filler in the required quantity $(5,10,15 \mathrm{~g}$ to corresponding to 10,20 and $30 \mathrm{wt} \%$ filler concentrations) was added to the polyethylene melt and mixed thoroughly with a stirrer until a uniform distribution of the filler through the melt is achieved. Stirring of the filler into the polymer melt in the hot saucepan was done for 3-4 min while heating continued. The procedure was followed to achieve $50 \mathrm{~g}$ composite mixture of 10,20 and $30 \mathrm{wt} \%$ filler concentrations.

The heated composite mixture was then transferred into a $200 \times 25 \times 15 \mathrm{~mm}$ mould (Fig. 3) coated with about $1 \mathrm{~g}$ grease as release agent to ensure conformity of the composites to the shape of the mould with the aid of ramming stick. The compounded material was allowed to remain in the mould for about an hour after which samples were removed from the mould and 

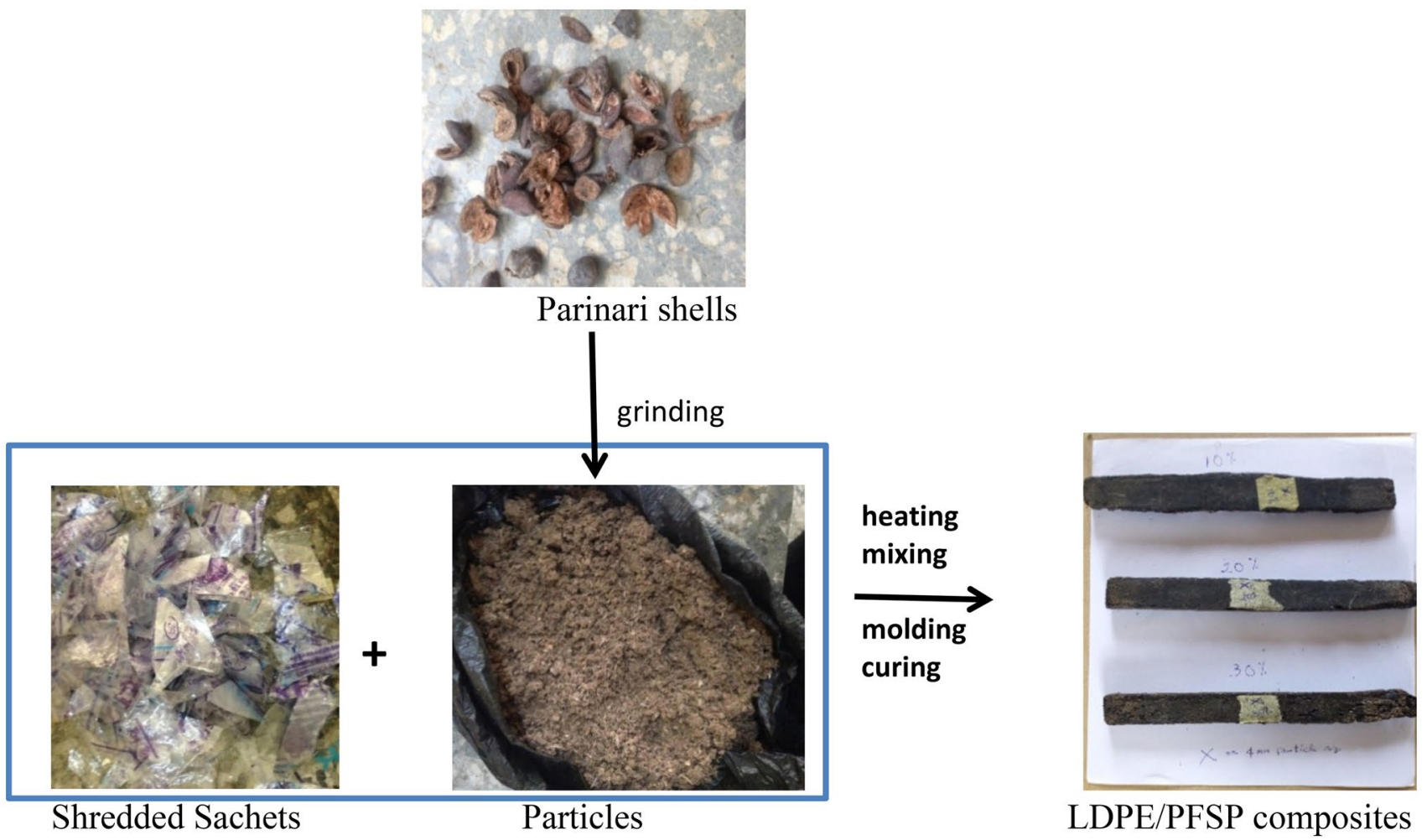

Fig. 2 LDPE/PFSP composite preparation

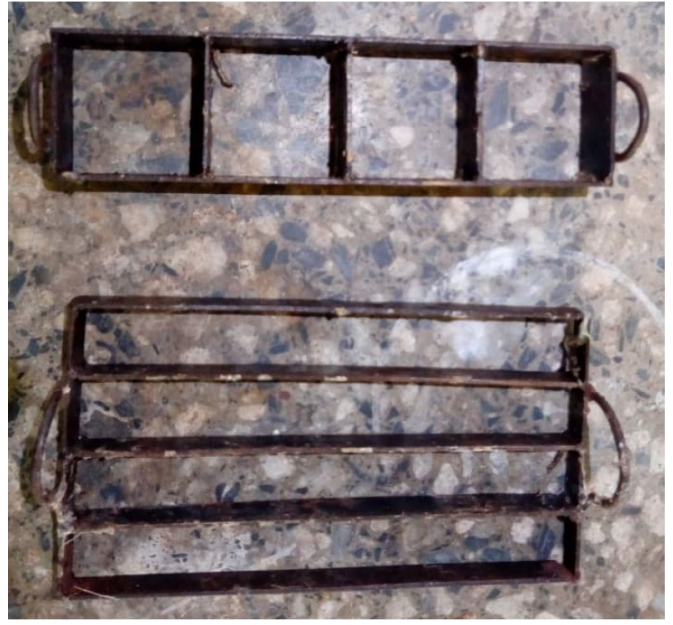

Fig. 3 Metal moulds

allowed to solidify further for an average of $4 \mathrm{~h}$ at room temperature.

\subsubsection{Characterization of PFSP-polyethylene composite}

2.2.3.1 Tensile strength The tensile tests were conducted on the biocomposite samples according to the ASTM D638 standard using a testometric universal test- ing machine (TUTM) model FS50AT (Testometric Co Ltd., UK). Specimens of $8 \mathrm{~mm}$ thickness were cut out using the mould. Two specimens/composition were used to obtain average values for tensile strength, elongation at break, and Young's modulus.

2.2.3.2 Compression strength The tensile strength of the biocomposites were tested using a universal testing machine according to the ASTM D695 standard. Tensile tests were carried out with the Universal Testing Machine. Specimens of dimension $\left(50 \times 50 \times 25 \mathrm{~mm}^{3}\right)$ were cut out using a mould of the same dimension. Two specimens were used to obtain average values for the compressive strength.

2.2.3.3 IZOD impact test The impact tests were done according to ASTM D256 standard on Avery Denison $150 \mathrm{~J}$ Impact testing machine, Model 6705U/33,122, Avery, California U.S. The tests were repeated using the IZOD scale while the mean values were recorded. The impact strength is a measure of the amount of energy that a material can absorb before fracturing under a high rate of deformation. The test is important because it is related to the product performance, service life and influences the important issues of product safety. 
2.2.3.4 Flexural test The flexural test was achieved using the same universal testing machine used for tensile test in accordance with ASTM D790 with a three-point bending geometry at a crosshead speed of $2 \mathrm{~mm} / \mathrm{min}$ to evaluate the flexural strength and modulus under a load cell of $1 \mathrm{kN}$. Mean values of the duplicate samples were obtained.

2.2.3.5 Hardness test The Brinell hardness test was carried out according to ASTM D78 to determine the hardness of the biocomposites. Mean values of duplicate tests were obtained for each filler-matrix composition.

2.2.3.6 Water absorption The water absorption study of the composites was determined according to ASTM D570. Samples were dried and immersed in distilled water and weighed at the end of $24 \mathrm{~h}$ (short term test) then for 4 days (long term test) to obtain the new changes in weight.

2.2.3.7 Morphology evaluation Morphological evaluation of the biocomposite was carried out by a scanning electron microscope SEM. The tensile fracture surfaces of the samples $\mathrm{X}_{1-30 \%}$ and $\mathrm{X}_{2-10 \%}$ were observed to study the relation between the morphology of the samples and the property changes/differences.

2.2.3.8 Biodegradability test The samples were cut into rectangular shapes $\left(100 \times 25 \times 15 \mathrm{~mm}^{3}\right)$ and buried in the natural soil around the chemical engineering laboratory, University of Ilorin. The ferruginous sandy soil was well-drained having sandy loamy surface and high sand fraction with soil pH of about 6 [23]. The test was carried out according to ASTM D5988. The biocomposites were buried in the soil and exhumed every 7 days, washed, dried, weighed and the samples were returned into the soil. The test was carried out for 5 weeks. The buried specimens were collected from the soil and the dirt removed by washing and drying. The weight of the sample before and after immersion into the natural soil was recorded. The degradation of the biocomposite samples was determined by observation of the changes in weight, shape, dimension and physical appearance [24].

\section{Results and discussion}

\subsection{Composite characterization}

\subsubsection{Tensile strength}

The tensile strength results were as shown in Fig. 4. Samples with particle size $X_{2}(0.84 \mathrm{~mm})$ and $X_{3}(0.42 \mathrm{~mm})$ showed a decreasing trend with increase in percentage of fibre content with the $10 \%$ fibre compositions possessing the highest stress bearing property before failing (fracture). This trend was also observed initially for particle sizes $\mathrm{X}_{1}(4 \mathrm{~mm})$ but for the $30 \%$ filler content. Observing the effect of the particle size variation on the PFSP/LDPE biocomposite, the particle size $\mathrm{X}_{2}(0.842 \mathrm{~mm})$ has the highest tensile stress property. This decreasing trend in tensile strength could be attributed to increasing filler-filler interaction which in comparison with the filler-matrix interaction could be more pronounced [17]. Another factor that could contribute to this reduction in tensile strength could be poor interfacial adhesion between the polar fiber and the nonpolar LDPE matrix which could initiate failure. Though the reason for the optimal tensile strength achieved at $X_{2}$ is not completely understood, it is most likely attributed to the more suitable particle size.

Figure 5 shows the Young's modulus results for the samples. Young's modulus seems to follow an increasing trend considering the variation of the filler composition. Young's modulus increased with increasing filler concentration in
Fig. 4 Tensile strength performance of the biocomposites with variation in filler composition (10, 20 and 30\%) and particle sizes $\left(X_{1}, X_{2}\right.$ and $\left.X_{3}\right)$

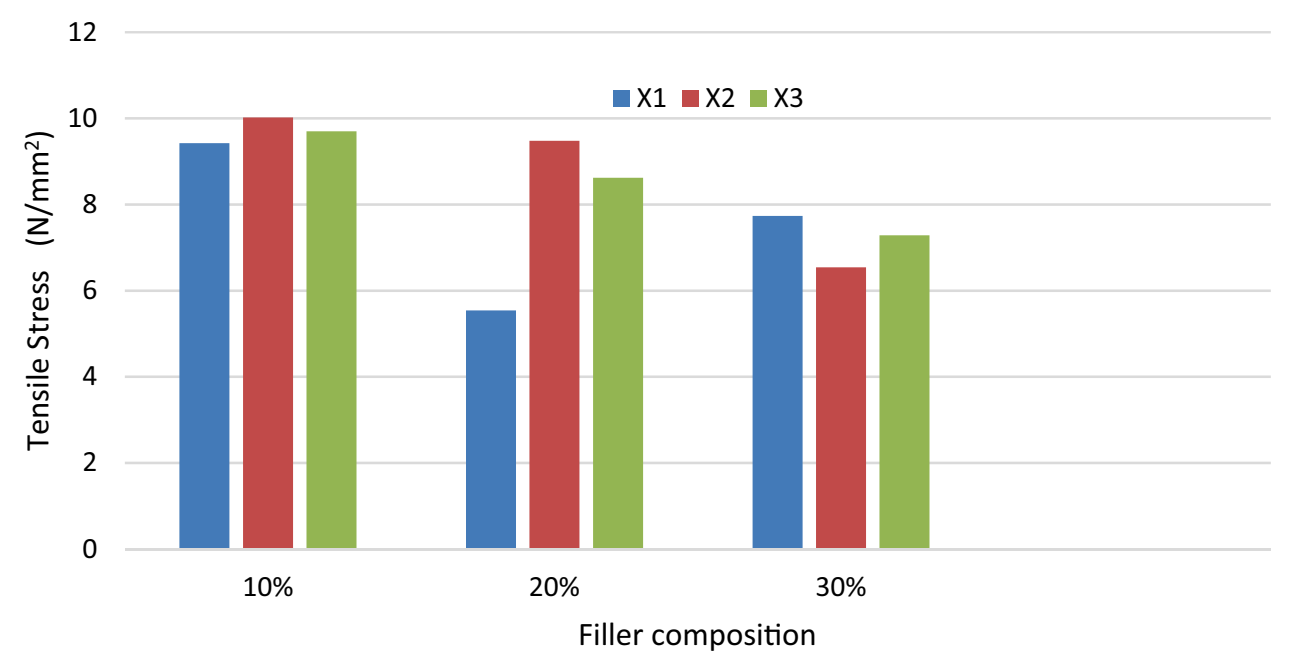


Fig. 5 Variation of Young's modulus with different filler content and particle size

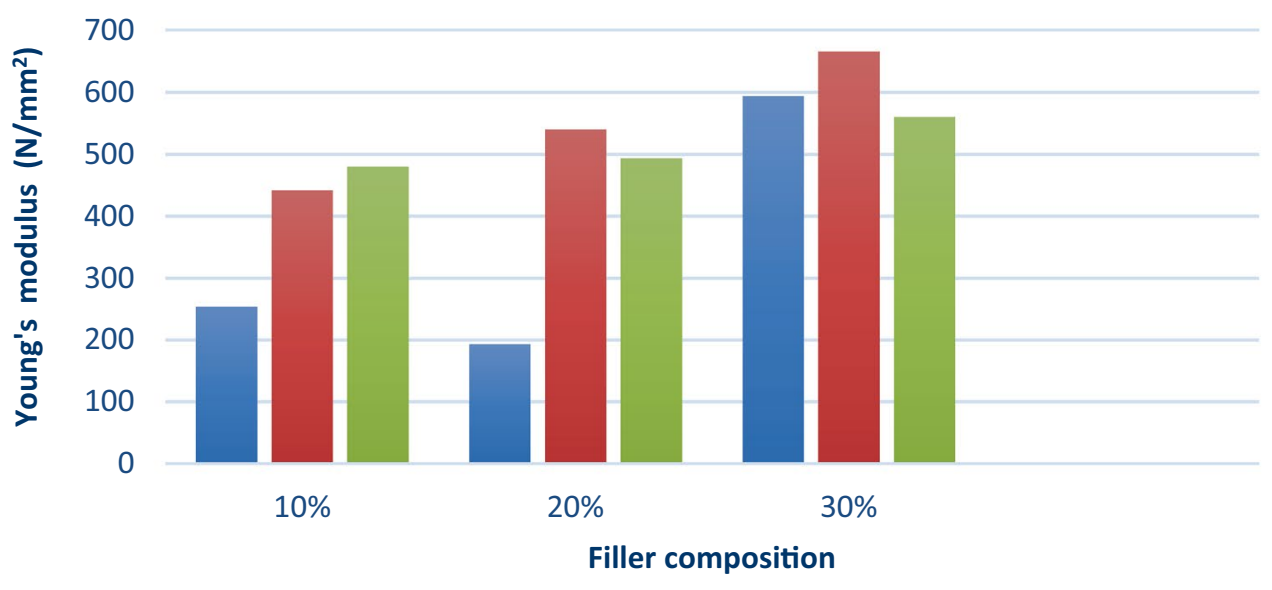

$\square \mathrm{X} 1 \square \mathrm{X} 2 \square \mathrm{X} 3$
$\mathrm{X}_{2}, \mathrm{X}_{3}$ and partly in $\mathrm{X}_{1}$. The samples with $10 \%$ filler content also followed the increasing trend of Young's Modulus with particle size distribution. This increase is attributable to the inclusion of the filler with relatively higher stiffness which tend to stand as obstacle to the movement of dislocation while the load is transferred from the matrix to the filler particles [16]. Particle size $X_{2}$ has the highest Young's modulus at 20 and $30 \%$ filler contents. Hence, higher stiffness was imparted to the composite with the filler. Highest stiffness would have been expected from $X_{1}$ samples but poor interfacial adhesion between the polar fiber and the nonpolar LDPE matrix seems to be more pronounced in larger particles leading to fracture.

Figure 6 shows the stress strain properties for the biocomposite samples. It was observed that sample $\mathrm{X}_{2-30 \%}$ (green curve) has higher brittleness compared to sample $X_{2-10 \%}$ (yellow curve) which has lower filler content for the same particle size. Hence, sample $\mathrm{X}_{2-10 \%}$ exhibited higher ductility and higher tensile strength compared to sample $\mathrm{X}_{2-30 \%}$. This implies that ductility decreased with increase in parinari particle contents. This phenomenon is attributable to the reduced fibre-matrix interaction with the presence of more fibre contents.

\subsubsection{Flexural strength}

Figure 7 shows the flexural strength of the biocomposite samples, indicating an overall decrease with increase in filler content. Also, considering the particle sizes $X_{1}$ and $X_{3}$, the flexural strength of these composite samples increased up to $20 \%$ after which it decreased. This result is similar to that obtained for peanut husk/LDPE biocomposite which increased up to $25 \%$ before decreasing with increase in
Fig. 6 Stress-Strain properties of the PSFP- LDPE biocomposites

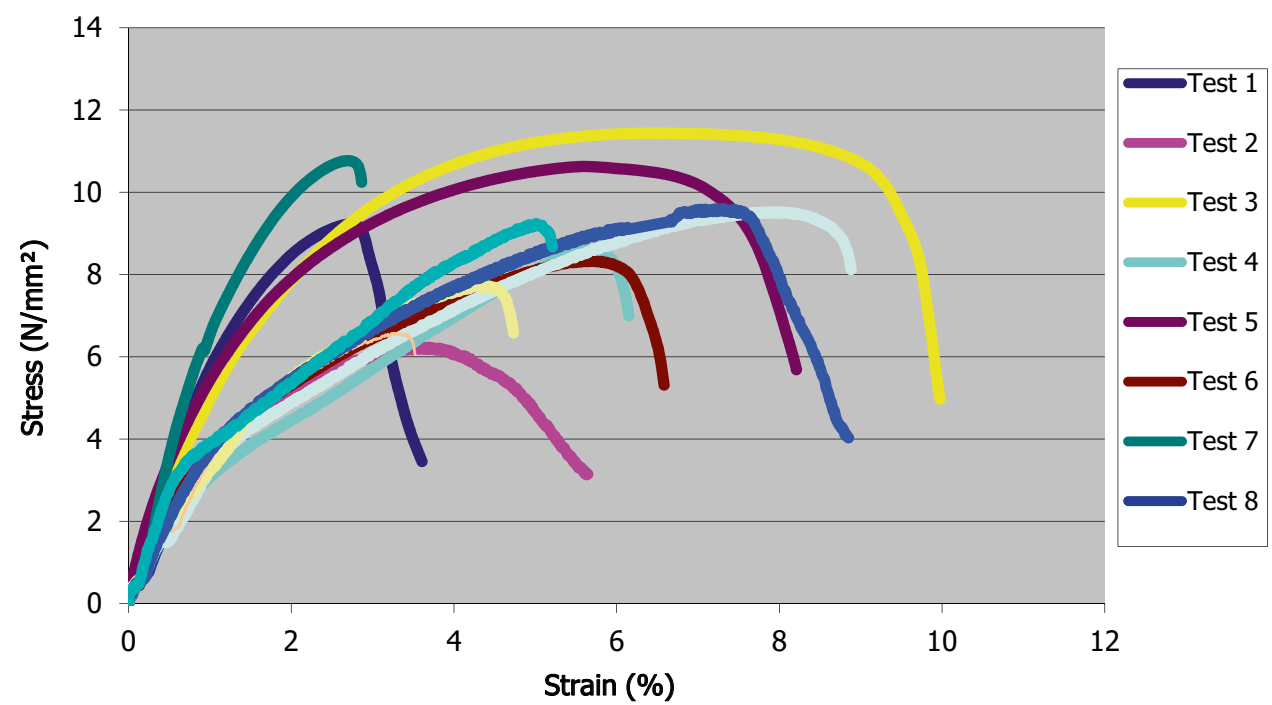

SN Applied Sciences 
Fig. 7 Variation of flexural strength with filler content and particle size
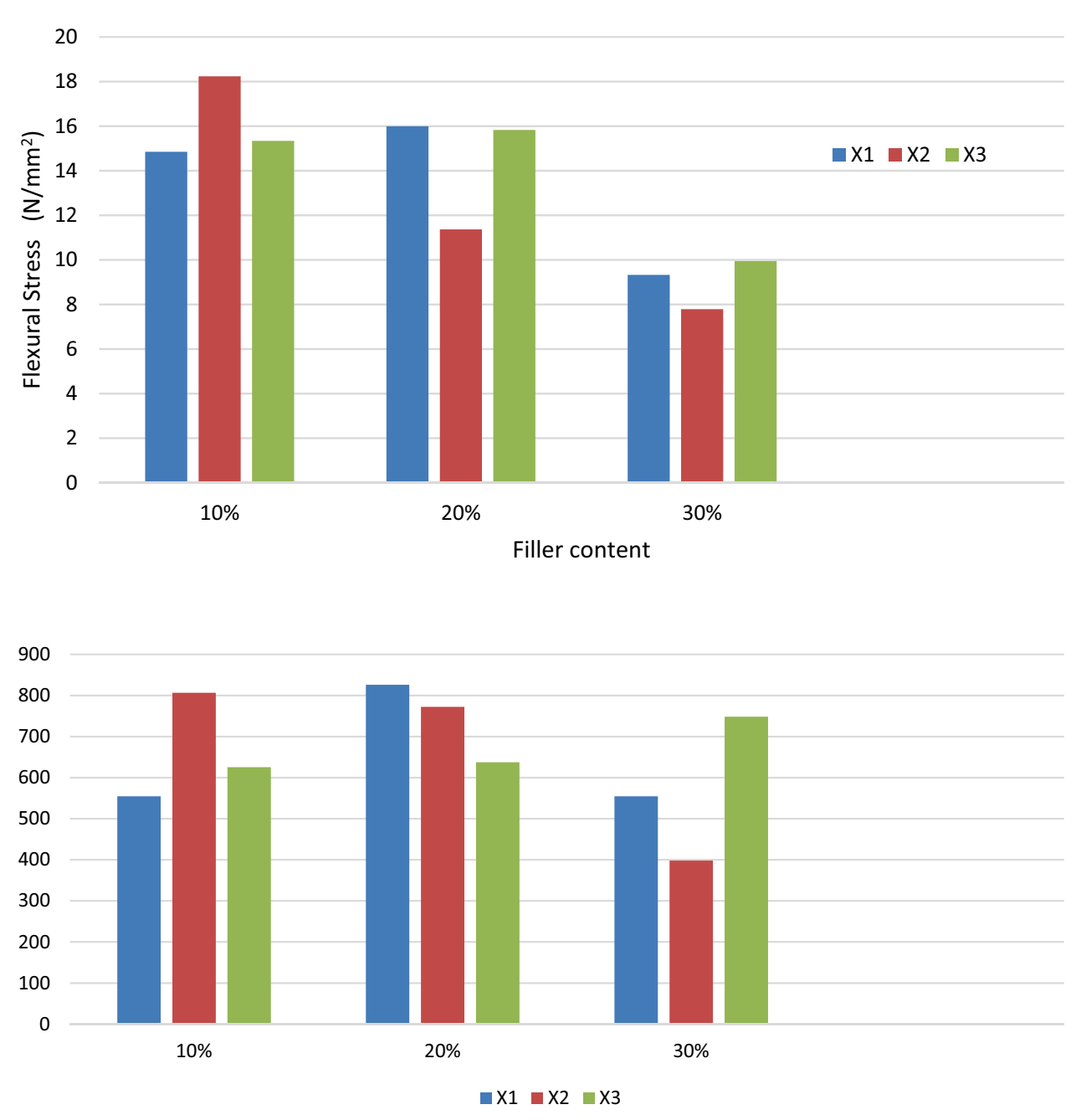

Fig. 8 Variation of bending modulus with filler composition filler content. This result is similar to those obtained in literature for natural fibre-filled polymer composites [17].

In Fig. 8, the flexural modulus of the composite favoured larger particle sizes at $20 \%$ filler contents. The increased bending modulus of the PFSF/LDPE composite can be traced to the rigidity imparted by PFSP which increased with particle size at $20 \%$ fibre content. The fibre in reinforcing the polymer could obstruct the free flow of the polymer chain and in doing so restrict the ability of the polymer to deform. Similar results have been obtained in literature [9].

\subsubsection{Impact strength}

Figure 9 shows that the impact strength decreased with increase in filler content while it seems to increase with decrease in particle size with $X_{3}(0.421 \mathrm{~mm})$ showing relatively higher impact strength owing to good fibre-matrix interfacial bonding with smaller particles. The decrease in impact strength indicates that the amount of matrix is not sufficient to distribute the stress effectively during a sudden impact [11]. This result is in line with earlier literature on LDPE. High filler content increases filler agglomeration, resulting in regions of stress concentration which require less energy for crack propagation.

\subsubsection{Hardness test results}

Figure 10 compares the hardness properties of the each biocomposite sample with respect to filler content and particle size. For particle size $\mathrm{X}_{1}(4 \mathrm{~mm})$ the hardness property increased with increase in filler content. The increase of the hardness can be attributed to the increase in stiffness caused by the presence of rigid fillers in the polymer matrix and the size of the matrix. [17]. However, the particle sizes $X_{2}(0.841 \mathrm{~mm})$ and $X_{3}$ $(0.421 \mathrm{~mm})$ showed a decrease and increase in magnitude for the $20 \%$ filler content and $30 \%$ filler content respectively. 
Fig. 9 Variation of impact strength with filler composition

Fig. 10 Variation of hardness with filler composition and particle size
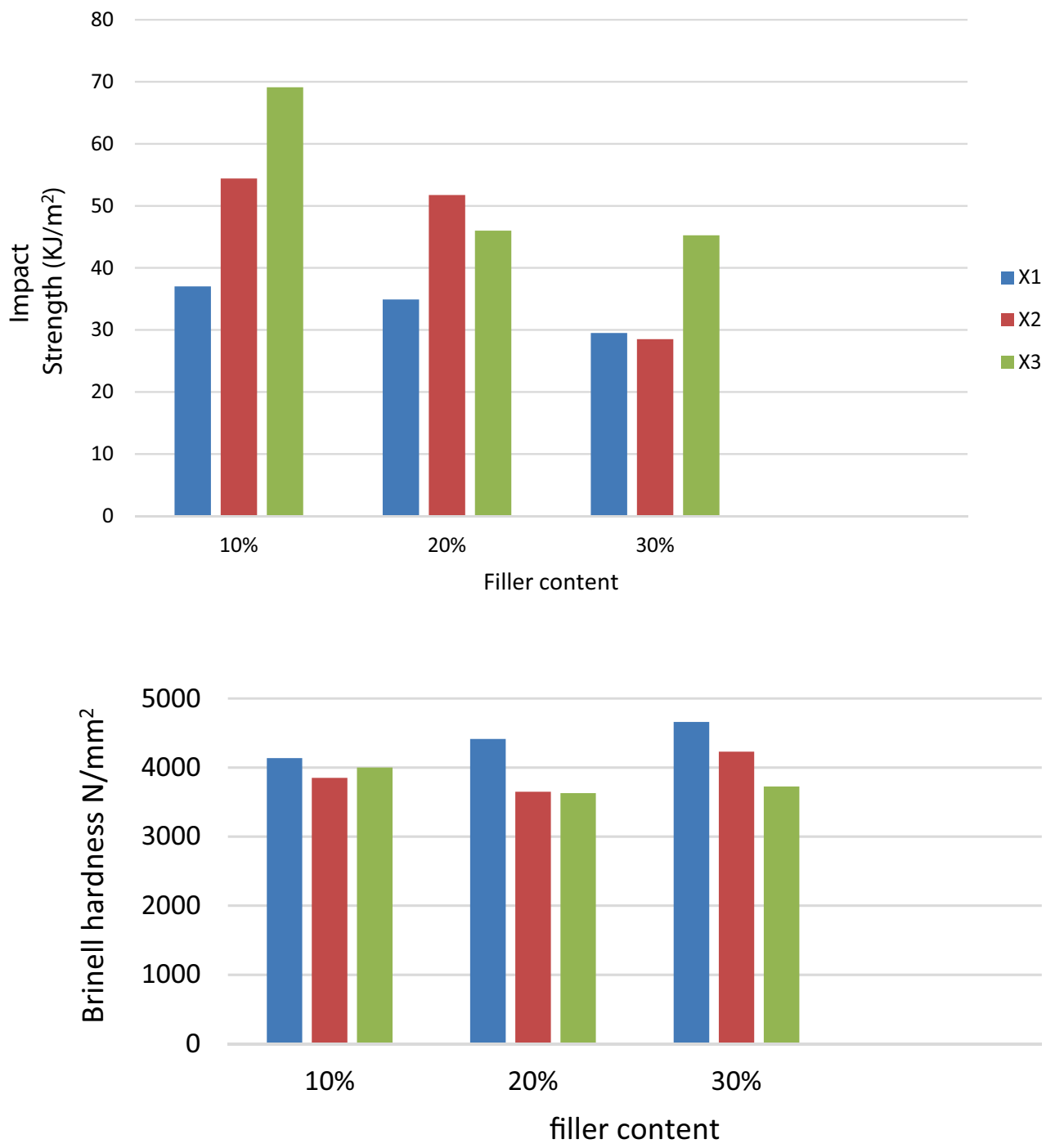

$\square \mathrm{X} 1 \square \mathrm{X} 2 \square \mathrm{X} 3$

\subsubsection{Compressive strength}

The compressive strength results indicated fair compressive strength property for all the samples. At maximum load applied $\left(16.276 \mathrm{~N} / \mathrm{mm}^{2}\right)$, there was no crack or fracture observed on the samples. The biocomposite compressed and increase in density upon each loading from the testing machine. This is indicative that the biocomposite is not suitable for applications where high compressive strengths are required.

\subsubsection{Water absorption test}

The water absorption test revealed that the biocomposite absorbed water after being immersed in water for four days with consecutive measurement of the weight for the period of study. The amount of water absorbed by the

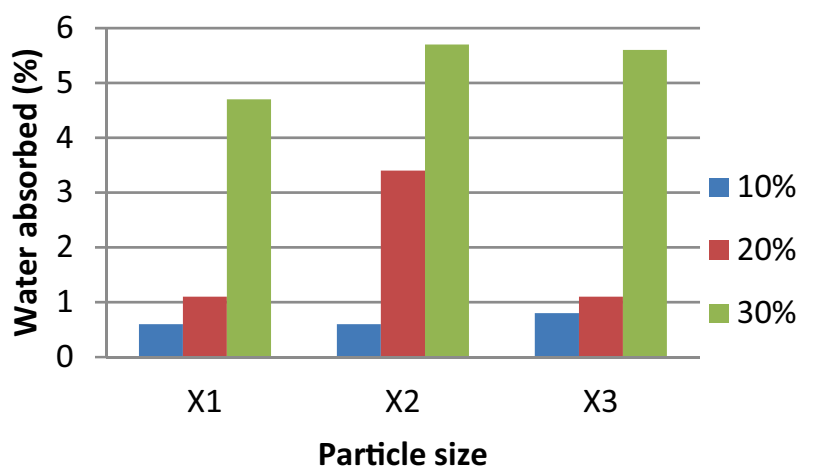

Fig. 11 Variation in water absorbed with particle size and filler contents 
biocomposite is a function of the temperature, fiber content the orientation of the fibres, permeability of the fibre, area of surface exposed, diffusivity, hydrophilicity of the individual components amongs others [25].

Water absorption test results in Fig. 11 show that the biocomposite samples absorbed more water with increase in filler content. This is expected as the hydrophilic nature of the lignicellulosic parinari fruit shell fiber can be linked to the amount of water absorbed. This is by virtue of the hydroxyl group present in abundance due to its cellulosic content. The presence of voids and cracks in the biocomposite can also contribute to the overall amount of water absorbed $[11,16]$. With more $20 \%$ filler content, water absorption became undesirably more prominent. Water absorption poses a challenge to the outdoor application of natural fiber-filled composites.

\subsubsection{Surface morphology}

The SEM micrographs of the samples $X_{2-10 \%}$ and $X_{1-30 \%}$ which showed more desirable properties are presented in Fig. 12. In a composite system in which a filler is incorporated into a polymer matrix, the morphology confers a strong effect on the mechanical properties. It is therefore imperative to observe the morphological changes of the system closely with the changes in mechanical properties. These samples showed the most favourable mechanical properties overall when compared with the rest of the samples. From the micrographs in Fig. 12, sample $\mathrm{X}_{2-10 \%}$ has an almost uniform distribution of the filler particles in the matrix. This uniformity of distribution is responsible for the ease of transfer of stress throughout the biocomposite sample, hence, the improved tensile stress, flexural strength, young modulus, ductility, water absorptivity. On the other hand, sample $\mathrm{X}_{1-30 \%}$ has the filler particles not as evenly dispersed through the matrix which might be responsible for it relatively lower performance compared to $\mathrm{X}_{2-10 \%}$ with respect to the above listed mechanical properties [16]

For sample $\mathrm{X}_{1-30 \%}$, the particle size $(4 \mathrm{~mm})$, however, has a positive influence on the recorded hardness which happens to rank highest overall and also on the compressive strength of the sample [24, 26].The poor performance under the other tests can be attributed to two factors: fibre agglomeration and poor fibre-matrix interaction. Interfacial adhesion between the particles and the matrix as well as good particle distribution in the matrix usually imparts good mechanical properties. However, poor adhesion between the filler and the matrix causes decrease in interfacial adhesion and is the reason for reduced mechanical performance. Similar findings were reported in literature $[27,28]$. Table 1 shows the elemental compositions of samples $X_{2-10 \%}$ and $\mathrm{X}_{1-30 \%}$.

\subsubsection{Biodegradeablity test}

Table 2 shows the results of the biodegradeability test on the biocomposite samples. It was observed that the percentage weight reduction is a function of the particle size of the filler and the filler composition. The percentage weight reduction increased with decrease in the particle size. This is so because a lower particle size means increased surface area available for aerobic degradation/ decomposition [24]. Sample $\mathrm{X}_{3-30 \%}$ had the greatest percentage weight decrease because it had the smallest size of filler particles $(0.421 \mathrm{~mm})$ and filler composition. This is because there is more fibre material available for decomposition. Hence, smaller particle size and higher filler contents favoured biodegradability of PFSP/LDPE composite.
Fig. 12 SEM micrographs of the samples $\mathrm{X}_{2-10 \%}$ and $\mathrm{X}_{1-30 \%}$ respectively
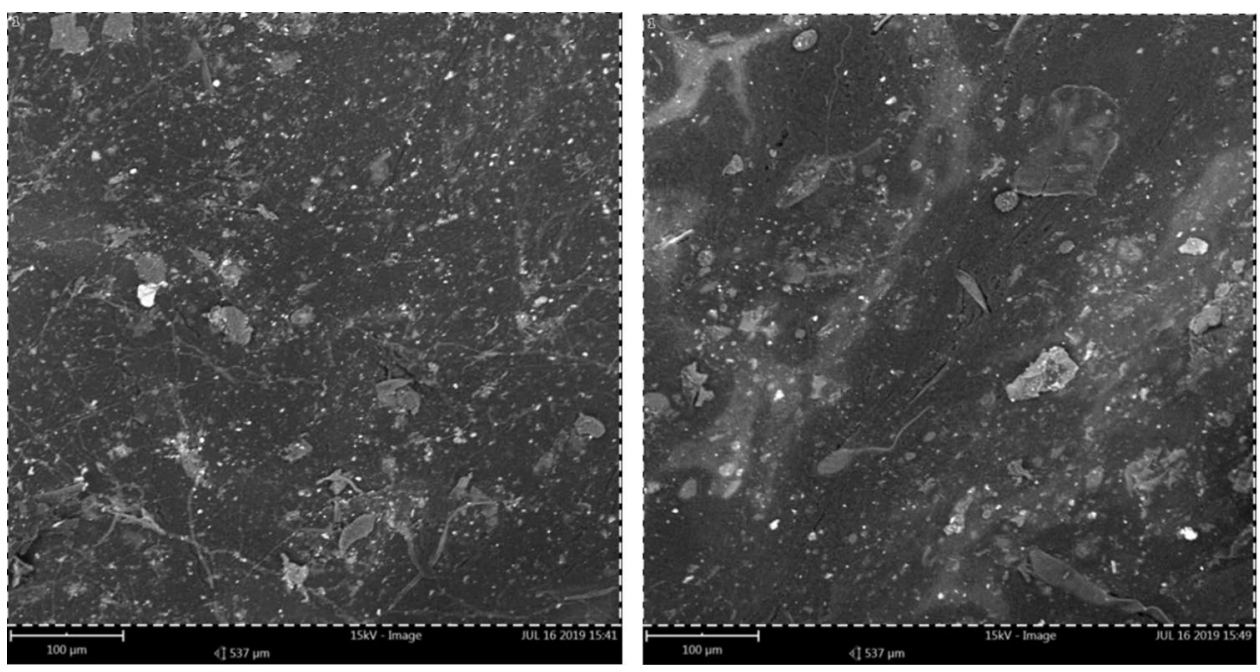
Table 1 Elemental compositions of samples $\mathrm{X}_{2-10 \%}$ and $\mathrm{X}_{1-30 \%}$

\begin{tabular}{lllllll}
\hline $\begin{array}{l}\text { Element } \\
\text { number }\end{array}$ & $\begin{array}{l}\text { Element } \\
\text { symbol }\end{array}$ & Element name & $\begin{array}{l}\text { Atomic conc } \\
\mathrm{X}_{2-10 \%}\end{array}$ & $\begin{array}{l}\text { Atomic conc } \\
\mathrm{X}_{1-30 \%}\end{array}$ & $\begin{array}{l}\text { Weight conc } \\
\mathrm{X}_{2-10 \%}\end{array}$ & $\begin{array}{l}\text { Weight conc } \\
\mathrm{X}_{1-30 \%}\end{array}$ \\
\hline 6 & $\mathrm{C}$ & Carbon & 88.81 & 88.31 & 83.95 & 84.88 \\
8 & $\mathrm{O}$ & Oxygen & 6.34 & 6.28 & 7.99 & 8.05 \\
7 & $\mathrm{~N}$ & Nitrogen & 2.84 & 4.58 & 3.14 & 5.13 \\
14 & $\mathrm{Si}$ & Silicon & 0.49 & 0.11 & 1.08 & 0.25 \\
20 & $\mathrm{Ca}$ & Calcium & 0.26 & 0.11 & 0.83 & 0.34 \\
13 & $\mathrm{Al}$ & Aluminium & 0.32 & 0.11 & 0.69 & 0.24 \\
26 & $\mathrm{Fe}$ & Iron & 0.12 & $\mathrm{NR}$ & 0.51 & $\mathrm{NR}$ \\
11 & $\mathrm{Na}$ & Sodium & 0.25 & 0.27 & 0.45 & 0.49 \\
16 & $\mathrm{~S}$ & Sulfur & 0.17 & 0.02 & 0.44 & 0.06 \\
12 & $\mathrm{Mg}$ & Magnesium & 0.17 & 0.05 & 0.33 & 0.10 \\
19 & $\mathrm{~K}$ & Potassium & 0.10 & $\mathrm{NR}$ & 0.32 & $\mathrm{NR}$ \\
15 & $\mathrm{P}$ & Phosphorus & 0.11 & $\mathrm{NR}$ & 0.28 & $\mathrm{NR}$ \\
\hline
\end{tabular}

NR Not recorded
Table 2 Biodegradeablity test

\begin{tabular}{llll}
\hline Samples & Wk1 & Wk5 & $\begin{array}{l}\text { \% Weight } \\
\text { reduction }\end{array}$ \\
\hline$X_{1-10 \%}$ & 20.918 & 20.737 & 0.865 \\
$X_{1-20 \%}$ & 24.717 & 24.654 & 0.25 \\
$X_{1-30 \%}$ & 24.445 & 23.991 & 1.875 \\
$X_{2-10 \%}$ & 23.270 & 23.196 & 0.318 \\
$X_{2-20 \%}$ & 22.154 & 22.141 & 0.05 \\
$X_{2-30 \%}$ & 21.365 & 21.109 & 1.198 \\
$X_{3-10 \%}$ & 25.070 & 25.047 & 0.179 \\
$X_{3-20 \%}$ & 25.812 & 25.635 & 0.686 \\
$X_{3-30 \%}$ & 19.954 & 19.142 & 4.069 \\
\hline
\end{tabular}

\section{Conclusion}

Biocomposites were succesfully produced from postconsumer LDPE water sachet polymer matrix using parinari fruit shell biomass wastes for reinforcement. The material exhibited satisfactory mechanical properties indicating desirable impact, tensile, and flexural properties which were influenced by filler content and particle sizes. The composite has good flexural, tensile and impact strength properties up to $20 \%$ filler composition. Hardness increased with filler content and particle size. The biocomposites have good ductility and are biodegradable. The new biocomposite possess relatively high compressive strengths suitable for applications where high compressive strengths are required. Conversion of postconsumer LDPE water sachet to biocomposite can be easily adopted as a cheap value added waste management process for low economy and a potential means of solving the global plastic waste crisis.

\section{Compliance with ethical standards}

Conflict of interest The authors declare that they no conflict of interest.

\section{References}

1. Wagner TP (2017) Reducing single-use plastic shopping bags in the USA. Waste Manag 70:3-12

2. Mierzwa-Hersztek M, Gondek K, Kopeć M (2019) Degradation of polyethylene and biocomponent-derived polymer materials: an overview. J Polym Environ 27:600-611

3. Abdel-Shafy HI, Mansour MSM (2018) Solid waste issue: sources, composition, disposal, recycling, and valorization. Egypt J Pet 27:1275-1290

4. Kumi-Larbi Jnr A, Yunana D, Kamsouloum P, Webster M, Wilson DC, Cheeseman C (2018) Recycling waste plastics in developing countries: use of low-density polyethylene water sachets to form plastic bonded sand blocks. Waste Manag 80:112-118

5. Wei-Fang $S$ (2013) Lecture notes in chemistry series. In: Carpenter B (ed) Principles of polymer design and synthesis, vol 82. Springer, Berlin, $\mathrm{p} 178$

6. Anour S, Abdalah K, Rabea E, Shalh A, Hassan E, Wael E (2018) The influence of LDPE content on the mechanical properties of HDPE/LDPE blends. Res Dev Mater Sci. https://doi.org/10.31031 /RDMS.2018.07.000672

7. Jordan JL, Casem DT, Bradley JM, Dwivedi AK, Brown EN, Jordan CW (2016) Effect of LDPE scrap composition on physical and mechanical properties of recycled PVC. J Dyn Behav Mater 2:411-420

8. Khanam PN, AlMaadeed MA (2015) Processing and characterization of polyethylene-based composites. Polym Compos Sci 1:63-79

9. Kim NH, Kuila T, Lee JH (2014) Enhanced mechanical properties of a multiwall carbon nanotube attached pre-stitched graphene oxide filled linear low density polyethylene composite. J Mater Chem A 2:2681-2689 
10. Huang $X$, Ke Q, Kim C, Zhong $H$, Wei $P$, Wang G, Liu F, Jiang $P$ (2007) Nonisothermal crystallization behavior and nucleation of LDPE/AI nano-and microcomposites. Polym Eng Sci 47(7):1052-1061

11. Pardhan RC, Naik SN, Bhatnagar N, Vijay VK (2009) Moisturedependent physical properties of jatropha fruit. Ind Crop Prod 72:183-191

12. Usman MA, Momohjimoh I, Gimba AS (2016) Effect of Groundnut Shell Powder on the Mechanical Properties of Recycled Polyethylene and Its Biodegradability. JMMCE 4:228-240

13. Ezenwa ON, Obika EN, Umembamalu C, Nwoye FC (2019) Development of ceiling board using breadfruit seed coat and recycled low density polyethylene. Heliyon $5: 02712$

14. Atuanya CU, Aigbodion VS, Obiorah SO, Kchaou M, Elleuch R (2016) Empirical models for estimating the mechanical and morphological properties of recycled low density polyethylene/snail shell bio-composites. JAUBAS 21:45-52

15. Moreno DP, Saron C (2017) Low-density polyethylene waste/ recycled wood composites. Compos Struct 17615:1152-1157

16. Oladele IO, Ibrahim IO, Adediran AA, Akinwekomi AD, Adetula YV, Olayanju TMA (2020) Modified palm kernel shellfiber/particulate cassava peel hybrid reinforcedepoxy composites. Results Mater 5:100053

17. Obasi HC (2015) Peanut husk filled polyethylene composites: effects of filler content and compatibilizer on properties. J Polym 2015:189289

18. Gu L, Ozbakkaloglu T (2016) Use of recycled plastics in concrete: a critical review. Waste Manag 51:19-42

19. Singh AK, Singh JK (2019) An efficient use of waste PE for hydrophobic surface coatings and its application on cotton fibers for oil-water separator. Prog Org Coat 131:301-310

20. Odetoye TE, Onifade KRA, Barkar MS, Titiloye JO (2013) Pyrolysis of Parinari polyandra Benth fruit shell for bio-oil production. Ind Crops Prod 44:62-66

21. Odetoye TE, Ogunniyi DS, Olatunji GA (2013) Studies on the preparation of Parinari polyandra benth seed oil alkyd resins. JAAPS 127(6):4610-4616
22. Ogunkunle O, Ahmed NA (2018) Response surface analysis for optimisation of reaction parameters of biodiesel production from alcoholysis of Parinari polyandra seed oil. Renew Energ 134:1320-1331

23. Oriola EO, Babatunde OR, Salami AA (2019) Soil characteristics of cassava growing ferralsols and ferruginous soils in kwara state. Nigeria SLJAE 1(1):87-101

24. Alias NF, Ismail H, Wahab MKA, Ragunathan S, Ardhyananta TH, Sung $S$ (2018) Physical, tensile, and biodegradability properties of cross-linked polyvinyl alcohol/palm kernel shell powder biocomposites. BioRes 13(3):5711-5724

25. Dhakal HN, Zhang ZY, Richardson MOW (2007) Effect of water absorption on the mechanical properties of hemp fibre reinforced unsaturated polyester composites. Comp Sci Technol 67: 1674-1683

26. Agunsoye JO, Talabi IS, Obe AA, Adamson IO (2012) Effects of palm kernel shell on the microstructure and mechanical properties of recycled polyethylene/palm kernel shell particulate composites. JMMCE 11(8):825

27. Picard $M C$, Rodriguez-Uribe $A$, Thimmanagari $M$, Misra $M$, Mohanty AK (2019) Sustainable biocomposites from poly (butylene succinate) and apple pomace: a study on compatibilization performance. Waste Biomass Valori 11:3775-3787

28. Li Z, Reimer C, Picard M, Mohanty AK, Misra M (2020) Recent advances in additive manufacturing of engineering thermoplastics: challenges and opportunities. Front Mater 7(3):1-12

Publisher's Note Springer Nature remains neutral with regard to jurisdictional claims in published maps and institutional affiliations. 